\title{
Os autores respondem
}

\author{
The authors reply
}

Los autores responden

\author{
André Luis Paes Ramos 1,2 \\ Marismary Horsth De Seta 1
}

doi: 10.1590/0102-311X00136019

As justificativas para a implantação do modelo de gestão por Organizações Sociais (OS) nos sistemas de saúde estão ancoradas, entre outros fatores, em um suposto aumento da eficiência. Dados sobre gastos municipais com saúde e atenção básica foram utilizados no estudo realizado, mas o principal foco analítico esteve sobre os indicadores de desempenho em atenção primária à saúde (APS) nas capitais da Região Sudeste que adotaram ou não o modelo de OS, com melhores resultados para as que não o adotaram.

Belo Horizonte e Vitória enfatizaram a Estratégia Saúde da Família (ESF) para a conversão do modelo de atenção, sem recorrer às OS. Apresentaram, em 2012, gastos maiores em saúde por habitante, ocasionando relativa perda de importância dos gastos per capita com APS. Belo Horizonte assumiu também a atenção de alta e média complexidades, geralmente maiores destinatárias dos recursos financeiros do SUS, diferentemente do Rio de Janeiro.

Outro argumento favorável às OS é sua agilidade para aquisições (pessoal e insumos), que permitiu rápida expansão de cobertura da ESF no Rio de Janeiro 1. Contudo, houve acelerada expansão da cobertura em Belo Horizonte entre 2002 e 2004, sem terceirização da gestão 2.

A partir de 2014, último ano do estudo, Belo Horizonte e Vitória sustentaram coberturas em APS e ESF em patamares elevados. Com cobertura inferior às de Belo Horizonte e Vitória, São Paulo se manteve relativamente estável e o Rio de Janeiro registrou queda nesses indicadores nos últimos dois anos, o que será objeto de futura publicação.

No Rio de Janeiro, foram extintas 239 equipes de saúde da família e bucal com a demissão de aproximadamente 1.400 profissionais, inclusive de agentes comunitários de saúde 3 , fato que a Secretaria Municipal de Saúde buscou justificar tecnicamente ${ }^{4}$. Esse episódio sugere que a manutenção da Administração Direta confere maior estabilidade à prestação de serviços em APS, e a terceirização resulta em flexibilidade dos vínculos com a possibilidade de precário monitoramento e controle interno ou externo - das OS 5 e de demissões em massa, na crise.

Importante destacar, ainda, a complexidade dos sistemas de saúde das capitais brasileiras, frequentemente as mais populosas cidades dos respectivos estados, mas, por outro lado, com maior poder de arrecadação para investimentos e custeio das ações de saúde.

Concordamos com os missivistas que, mormente em grandes cidades, acentuam-se as desigualdades entre bairros e comunidades, nos aspectos demográficos, étnicos, econômicos e sociais, que
1 Escola Nacional de Saúde Pública Sergio Arouca, Fundação Oswaldo Cruz, Rio de Janeiro, Brasil. 2 Hospital Universitário Gaffrée e Guinle, Universidade Federal do Estado do Rio de Janeiro, Rio de Janeiro, Brasil.

\section{Correspondência} A. L. P. Ramos Rua Dionisio Ertal 69, bloco 2, apto. 904, Nitéroi, $R J$ 24240-020, Brasil.

andrepaesramos@gmail.com 
impactam a saúde. Desigualdades (diferenças) e iniquidades (diferenças evitáveis e injustas) sociais e em saúde são recorrentes na literatura científica, bem como os métodos para analisá-las. Por exemplo, Ribeiro \& Silva 6 descrevem desigualdades intraurbanas em internações na cidade de São Paulo, e Magalhães \& Morais Neto 7, em Goiânia.

Como dizem diversos autores, nosso país "apresenta importantes desigualdades sociais, que ainda se refletem em persistentes desigualdades em saúde. A descrição e monitoramento (...) são fundamentais para o direcionamento de políticas de saúde, com foco em grupos mais vulneráveis” 8 (p. 1) e em populações vulnerabilizadas.

Desigualdades e iniquidades intraurbanas ocorrem nas capitais também na APS, no entanto, o estudo focalizou o modelo de gestão adotado pelos governos municipais nos respectivos sistemas de saúde no âmbito da APS, bem como o desempenho nas quatro capitais, sendo a unidade de análise o município capital. Reconhecemos as diferenças entre as cidades - e buscamos caracterizá-las no estudo, mas o objeto era o desempenho nos indicadores em APS mediante dados municipais de acesso público. Ademais, é provável que as diferenças decorram de outros determinantes sociais da saúde, que incluem também a diferenciação entre áreas com predominância de usuários de planos de saúde ou do SUS.

Por fim, salientamos que estudos longitudinais são necessários para o prosseguimento da avaliação do modelo, principalmente considerando a recente Portaria da Secretaria do Tesouro Nacional 9 que orienta a inclusão das OS no cômputo do teto de gastos com o pessoal da Lei de Responsabilidade Fiscal, a partir de 2021. Essa inclusão pode gerar desestímulo ao crescimento da implantação das OS e disseminar a prestação de APS por meio das Organizações da Sociedade Civil (OSC) 10 ou de Parcerias Público-Privadas 11. E ainda há o risco de "pejotização" na APS, ou seja, a disseminação da contratação de profissionais como pessoas jurídicas.

\section{Colaboradores}

A. L. P. Ramos e M. H. De Seta participaram de todas as etapas da elaboração do texto.
Informações adicionais

ORCID: André Luis Paes Ramos (0000-0002-32627321); Marismary Horsth De Seta (0000-00034764-5159). 


\section{Referências}

1. Soranz D, Pisco LAC. Reforma dos cuidados primários em saúde nas cidades de Lisboa e Rio de Janeiro: contexto, estratégias, resultados, aprendizagem, desafios. Ciênc Saúde Colet 2017; 22:679-86.

2. Giovanella L, Escorel S, Mendonça MHM. Estudos de caso sobre implementação da Estratégia Saúde da Família em quatro grandes centros urbanos. Relatório final. Rio de Janeiro: Escola Nacional de Saúde Pública Sergio Arouca, Fundação Oswaldo Cruz; 2009.

3. Junqueira F. Prefeitura anuncia corte de 239 equipes de saúde da família e saúde bucal na Cidade do Rio. Extra 2018; 30 out. https://extra. globo.com/noticias/rio/prefeitura-anun cia-corte-de-239-equipes-de-saude-da-fami lia-saude-bucal-na-cidade-do-rio-23200159. html.

4. Secretaria Municipal de Saúde do Rio de Janeiro. Reorganização dos serviços de atenção primária à saúde: estudo para otimização de recursos. https://www.abrasco. org.br/site/wp-content/uploads/2018/11/ REORGANIZA\%C3\%87\%C3\%83O-DOSSERVI\%C3\%87OS-DE-ATEN\%C3\%87\% C $3 \% 83$ O - PRIM \% C $3 \% 81$ RIA - A - S A \% C3\%9ADE-ESTUDO-PARA-OTIMIZA\% C3\%87\%C3\%83O-DE-RECURSOS.pdf (acessado em 15/Jan/2019).

5. Silva VM, Lima SML, Teixeira M. Organizações Sociais e Fundações Estatais de Direito Privado no Sistema Único de Saúde: relação entre o público e o privado e mecanismos de controle social. Saúde Debate 2015; 39(spe):145-59.

6. Ribeiro H, Silva EC. Desigualdades intraurbanas em internações hospitalares por doenças respiratórias e circulatórias em uma área da cidade de São Paulo. Cadernos Metrópole 2016; 18:461-80.
7. Magalhães ALA, Morais Neto OL. Desigualdades intraurbanas de taxas de internações por condições sensíveis à atenção primária na região central do Brasil. Ciênc Saúde Colet 2017; 22:2049-62.

8. Silva ICM, Restrepo-Mendez MC, Costa JC, Ewerling F, Hellwig F, Ferreira LZ, et al. Mensuração de desigualdades sociais em saúde: conceitos e abordagens metodológicas no contexto brasileiro. Epidemiol Serv Saúde 2018; 27:e000100017.

9. Secretaria do Tesouro Nacional. Portaria no 233, de 15 de abril de 2019. Estabelece regra transitória em razão da necessidade de definição de rotinas e contas contábeis, bem como classificações orçamentárias para operacionalização do item 04.01.02.01 (3) da 9a edição do Manual de Demonstrativos Fiscais (MDF), aprovado pela Portaria STN no 389, de 14 de junho de 2018. Diário Oficial da União 2019; 16 abr.

10. Brasil. Lei no 13.019, de 31 de julho de 2014 . Estabelece regime jurídico das parcerias entre a administração pública e organizações da sociedade civil para a consecução de finalidades de interesse público e recíproco, mediante execução de atividades ou de projetos previamente estabelecidos; e altera as Leis no 8.429 , de 2 de junho de 1992, e 9.790 , de 23 de março de 1999. Diário Oficial da União 2014; 1 ago.

11. Brasil. Lei no 11.079 , de 30 de dezembro de 2004. Institui normas gerais para licitação e contratação de parceria público-privada no âmbito da administração pública. Diário Oficial da União 2004, 31 dez.
Recebido em 17/Jul/2019

Versão final reapresentada em 27/Ago/2019

Aprovado em 28/Ago/2019 